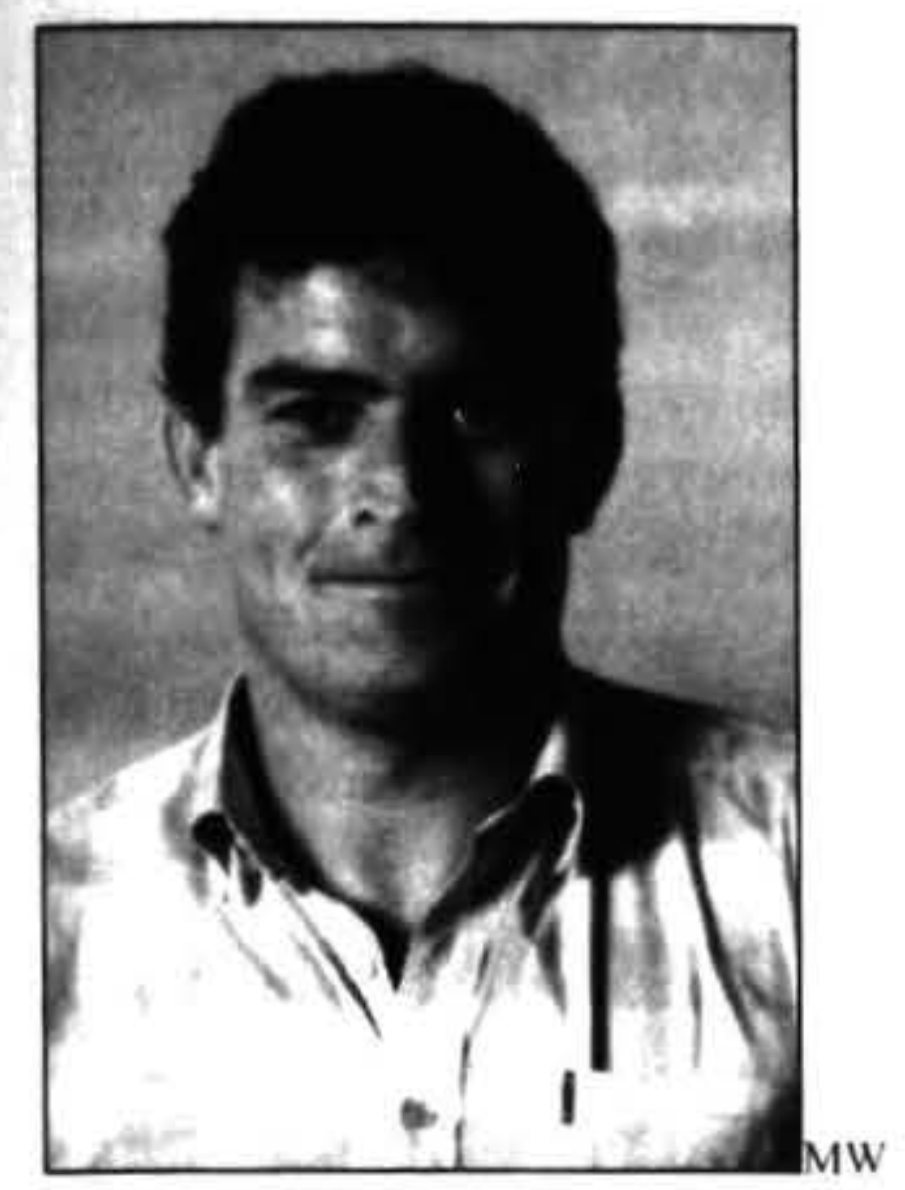

\title{
MEETING TOMORROW'S SKILL NEEDS THROUGH PRE- EMPLOYMENT TEACHING PROGRAMMES FOR NEW ZEALAND SCHOOLS
}

\author{
Mark J. Williams \\ Williams Construction, \\ Auckland
}

Alan Williams

Williams and Partners Ltd, Palmerston North

\begin{abstract}
This paper will review work in progress on a teaching programme for students whose formal education tends to terminate at the secondary school level. The perception of need is based initially on the structural shifts taking place in industrial demographics which postulate a decline in the new entrant replacement rate in western style development economies, and a rising dependence on indigenous labour supply. Theses trends suggest it is time to reconsider the case of New Zealand, using Torsten Husen's seminal concept of the reserve of talent. It proposes a triadic model as a possible strategic tool, in which a given school and its local community, together with a designated employing firm in a specific category of skilled work. collaborate in a combination of teaching-learning and practical exercises. The intention is to raise the level of information available to job--seekers, employing firms and the socio-economic perception of employment opportunities, within the comimunit: While the course is intended to have a general application across industries it will utilize as an example. a working model of the civil engineering industry; which has been the focus of some preliminary testing.
\end{abstract}

\section{Introduction}

There is growing international evidence that the normative assumptions that underlie the intergenerational movement of stocks and flows in the labour market increasingly have to adapt to structural changes in both their nature and form. We can identify a number of primary shifts, which are now found to be present in many national economies and which increasingly create the need for governments to come to terms with a changing industrial demography. The relative decline in fertility is now identified as a major international phenomenon, which is reflected in turn in many western countries, by the growing presence of an ageing labour force. This in turn is producing an international shortage of skilled labour, in both the developed and developing worlds.

It is also having an important effect on the classical model of the migration of labour, with in many cases, the duration of a skilled worker's stay in a given national location, being dictated by the terms of contract, rather than by the intention of permanent residence. This is supported by transportation systems that now allow managers for example, to be deployed, on regular cycles between countries in the service of multinational enterprises. This is a class of traveller's described in a recent study, as "road warriors" (Welch and Worm 2006).

The cumulative dynamics of these increasingly globalised developments raises some major issues for national economies with regard to the continuity of labour supply in the medium to long term. This paper will attempt to address a very specific aspect of the problem, by suggesting that greater attention should be paid to the maximisation of an existing and potential source of labour supply to be found in that proportion of the population who complete their formal education in low decile secondary schools, either before, or at the age when the rules of compulsory attendance are no longer personally applicable.

What will be described below in practical detail, is the suggestion that such a population might comprise a "reserve of talent", whose ability to contribute to economic growth might best served by a more customised form of pre-entry training to the labour force (Husen 1983; Husen and Postlethwaite 1983); Husen and Tuijnman 1991). The need for such programmes designed for application in New Zealand, to accommodate the current demographics of the reserve of talent including both the Maori and the major ethnic 
minorities, has also drawn on the important work of Mason Durie. This introduces the larger context of community as well as social and cultural identity, as a shaping component of the teaching-learning dynamic.

It remains to note that the educational assumptions shaping this teaching model intentionally depart from the drivers of social and economic status (SES) that today inform the public perceptions of what constitutes quality education. The purpose here is to offer a set of practical options that will allow schools to deploy a much broader range of educational experiences for their students. In doing so it is also hoped that the need for labour market strategies that will maximise the skill potential of the indigenous population component of new entrants, will also be identified.

\section{Theories That Shape the Working Model}

The conceptual basis of the paper has been strongly influenced by Durie's concept of "Whare Tapawha" with its stress on the four dimensions of physical, mental, social and spiritual well being (Durie 2004). It has also taken cognisance of the notable shift in the concept of essential learning categories found in the Curriculum Stocktake Report to the Minister of Education (Dept. of Education 2002). Consideration has also been given to the Youth Development Strategy, with its focus on the student and the family as well as the community within which they live. The strong formative aspect of these latter locations on the shaping of perceptions of future employment, have also been an important influence on modular design.

A further number of theoretical studies have also been considered as forees shaping the curriculum notably, the important ability to develop positive self esteem and recognition of diversity in others (Denman Sparks, 1989). which has been linked to the notion of learning as a community of enquiry, in which the interactive relationship between teacher and pupils shapes the questions and answers that inform the dynamic of classroom activity (Lipman, 1988). In turn, the essential influence of learning as an activity grounded in a social environment and its effects on the process of passage from interdependent to independent learning is also given support through a key workshop exercise that will be described below (Van der Veer and Valsiner, 1994; Vygodskaya and Lifanova, 1999). It is also important to observe at this juncture, that the works of Piaget, Bruner and Maslow have done much to shape our thinking.

\section{The Purpose of Pre-recruitment Studies}

The primary educational purpose of the programme is to introduce students in low decile schools to the concept of skilled work as a practical activity as well as the possible opportunities that may be open to them at the point when they seck to enter the labour market. The initial model assumes a Year Eight pilot study, but it is intended that a degree of flexibility in usage, will allow for prescription and curriculum modifications, so that the programme may be further adapted for secondary school use.

The specific school populations that will be identified as the focus of the programme will have a significant number of pupils who tend to either leave formal education at the end of compulsory secondary period or even before. The primary stress will be on preparatory learning for labour market entry with the expectation that any formal studies post school will be directly related to the development of various industrial skills. Logic dictates that the largest proportion of entrants will come from low decile schools, but this does not preclude higher decile schools from using the programme.

The educational purpose is to develop an understanding of industry both in terms of the broad economy, and in the specific contexts of given sectors. From the individual student's perspective, the further intention is to encourage a wider personal perspective on the scope and roles of skilled employment, and the possibility of a strong congruence between personal interest and available opportunities in the local or even sectoral labour market.

The proposed model also prescribes a key role for both schools in both specific localities and firms as agencies collaborating for mutual benefit. While the preponderance of SMEs in New Zealand tends to delimit to some extent the sponsorship of pre-entry programmes, the innovative role of large firms as industry leaders seeking new trainees can be very important. With this in mind, a first pilot programme is already in its opening phase as a North island school supported by one of the country's leading civil engineering firms. Discussions with senior teachers have also indicated a strong degree of interest in what can be described as "real time real life" learning.

\section{The Operational Curriculum and its Teaching Learning Prescriptions}

\section{The programme consists of three linked activities.}

A lesson plan with its contents designed by selected staff with specific customisation to fit the school and community in which it is located. Strong links to the mainstream curriculum is maintained by ensuring that the teaching learning cycle continues to ensure prescribed learning outputs. In addition to components of the Social Sciences curriculum, various aspects of the English syllabus would be developed as a function of the overall programme.

The division of the class into self-selecting or nominated groups. Each group to be charged with information creating tasks, relating to the roles played by the specific industry within the larger context of the specific community. The final assessment to be based on an oral presentation by each group to the rest of the class.

The final integration of the work done by each group into a virtual community model, with stress to be given to the way in which viable network relationships are built up. 
Visits by subject experts from the sponsoring firm, would allow for presentations on each aspect of the planning process. This activity will be supported in turn by site visits, which would allow for the practical demonstration of the skills involved.

\section{The Planning Activity in Action}

It has already been noted that an initial pilot programme has been instigated, with support from a major civil engineering company. This has allowed five task groups to be created within a selected class. Each group has a specific remit, which calls for them to review a specific industrial sector with further a requirement that they present a final report for peer review by all the other groups. The exercise also aims to expand student's perceptions of the ways in which industry underpins a whole range of social and economic activities within a New Zealand community.

The five categories to be investigated are listed as follows:

- Roads and Bridges;

- Sewer Treatment and Control,

- Water Treatment and Distribution;

- Housing, Schools, Commercial and Public Buildings, Churches and Community Centres;

- Hospitals and Emergency Services.

The exercise will require the students to collect data in order to identify and describe the engineering services needed for the following group of community agencies:

- Schools, Roads and Housing

- Factories and Shopping areas;

- Sewer Systems, Water Supplies and Waste Disposal;

- Community Leisure Centres and Churches

- Street Lighting and Transport Systems;

- Hospitals; and Emergency Services.

The sector review exercise on completion will then be folded into a third set of tasks that would aim to create a virtual community setting in which all of these activities would be present and active. This would take the form of an integrated scale model developed within a careful set of specifications as a three dimensional view of the industry's multi-various roles in the larger society. The virtual community would have a population of one thousand people drawn from a cross section of peoples and based on gender, race and cultural diversity.

\section{Possible Barriers to Programme Development}

Problems expressed as a reluctance to take part in the programme may be found within the community at large, which militates against it becoming the third important leg of this triadic model. In the first case class members, given the dynamics of ethnic group relationships in the external community, may be unwilling to interact with students from other cultural groups. This may be offset by an intervention whereby the class evolves a treaty that allows for mutual commitments to the learning process.

In turn communities with large populations that may have negative personal experiences of schools as a learning environment could be reluctant to become involved at the essential parent level. The need to overcome the inevitable assumption that education has little social or economic purpose after pupil leaves school, could possibly be assisted by careful attention to cultural protocols that allow parents to be part of the total activity.

A third factor for consideration would involve the power relationships that exist between a school's trustees as managers and powerful and significant groups in the larger community. For example a high decile school, whose benchmark for excellence is based on the proportion of places they obtain in the tertiary sector, may well, have little room for programmes that stress practical skills as the intended outcome. On the other there might well be a fit between this programme and those pupils whose interests and abilities might well be served by an apprenticeship after secondary school. The anticipation is however that the major focus will be upon low decile schools located in or close to industrial areas. This will allow for the effective liaison between schools and firms who wish to sponsor the programme within their locality.

\section{The Key Role of the Industrial Company}

An essential assumption of the model refers to the active participation of industrial companies as partners with schools in the overall purposes of the programme. In terms of the demands for labour market strategies that maximise indigenous capacities of school leavers especially in the key areas of industrial skill, there are several roles that major companies might play.

From the corporate perspective the material benefits might well lead to a consistent and long term relationship leading progressively to career recruitment. In effect the course might well be folded into the planning of human resource initiatives that encourage students to develop over time, personal strategies that include possible direct entry to the firm.

The programme also promises a larger spin-off in the sense that the structure of firms in New Zealand remains, in employment terms, skewed toward the SME sector, with an average labour force to be found in the $0-5$ to 0 10 range. This raises manifest difficulties for policies that stress national as opposed to highly localised planning for industrial growth. Lead firms of proportionate size may therefore become in a sense models and possible mentors for industrial strategies that attempt to maximise the takeup and training of school leavers.

It is also worthy of comment that in an age where some notions of corporate governance, have increasingly become subject to moral and ethical condemnation, the concept of the good corporate citizen, might well be became a valuable identifier particularly for sectoral lead 
firms which exemplify the notions of market success and operational efficiency.

\section{The Current Status of Research and Programme Development}

The current state of work on this project now requires that a series of pilot programmes be introduced in order to validate, its operational utility and performance outcomes. There can be no doubt that the medium to long term demographics signal that positive fertility rates in terms of indigenous labour market supply, will increase the non-European component of the population, while at the same the European component of the population will return a negative fertility rate. With this in mind the need to concentrate on the labour market potential of both indigenous and ethnic minorities takes on a new urgency.

Research is also needed in order to adjust the operative design and functions of the individual courses to accommodate the specific circumstances faced by individual schools. By definition and as a function of the original model, the task of syllabus design will rest with the individual school, which will then have moral and ethical rights to that very specific and localised programme. The raises the further need for on-going liaison between the originators of the model and the designers of each customised course. It should also be noted that this point, that the organization that conceived of the programme is not a public research institute, but rather. a small commercial consultancy, which is currently self-funding the programme as a working project.

In the initial exercise that is currently in its early post design phase, the school has been able to obtain funding through firm based sponsorship, by a very large company. Quite apart from the question of ethical rights to the ownership of the school's programme, the serious question arises with regard as to the ability of a school to obtain such support, in areas of equal potential, but lesser economic clout. The exercise cited is located in New Zealand's largest industrial conurbation. The question is can such support be generated in smaller centres with less varieties of industrial production? It remains to advise that the search for possible developmental funding will commence very soon.

\section{Conclusion}

The ultimate purpose of the model described above has a dual focus. For while it has demonstrable utility as an educational tool, aimed at a key but vulnerable group within the school system. it is also intended as a means to offset the increasing demand for skilled workers that is now emerging internationally as a major problem for developed and developing economies alike.

Reliance on the net migration of skilled workers is becoming an increasingly counter factual policy since the growing tendency for competitive and multiple market incentives accompany the decision to transfer often require a proportionate reward that then distorts prevailing rates in the home market. It is further complicated by the already noted tendency for an individual's to stay for the length of the contract, rather than adopt the role of a permanent migrant. The essential mobility of modern skilled workers is also reflected in the fact that it is now possible to live in one country and work in another.

As a last comment, the model proposed above, is not intended to be a silver bullet, but rather, a call for more efficient labour market strategy that will at least maximise available labour market potential recruited from New Zealand's indigenous human resource base.

\section{References}

Bell, A. and Carpenter, V. (1994). Education's role in reproducing social class in Aotearoa, In Coxon, E. et al. The Politics of Learning and Teaching in Aetearoa, Palmerston North: The Dunmore Press.

Bishop, P. and Davis, G. (2002). Mapping public participation in policy choices. Australian Journal of Public Administration, 61, 14-29.

Bourdieu, P., Nice, R. and Bottomore, T. (1990). Reproduction in Education. Society and Culture. London: Sage.

Bruner, J. (1977). The Process of Education, Massachusetts: Harvard University Press.

Bryant, J. (2003). Demographic Change and New Zealand Economic Growth. Treasury Working Paper, 03/04. Wellington: The Treasury.

David, P.A. (2001). Knowledge. Capabilities and Human Capital Formation in Economic Growth. New Zealand Treasury Working Paper 01/13. Wellington: The Treasury.

Denman-Sparks, L. (1989). Anti-bias Curriculum Tools for Empowering Young Children. Washington DC: National Association for the Education of Young Children.

Durie, M. (2004). Whare tapa wha a Maori model of a unified theory of health, Journal of Primary Prevention. 25(1), 41-57.

Elley, W. and Irving, J.C. (1982). A socioeconomic index for New Zealand, based on levels of education and income (1966 Census). Journal of Educational Studies. 153-167, NZCER.

Glass, H. and Choi, W.K (2001). New Zealand Treasury Working Paper (01/22. Wellington: The Treasury.

Husen, T. (1983) An Incurable Academic. London: Pergamon Press. 
Husen, T. and Postlethwaite, T.N. (1983). The International Encyclopedia of Education. London: Pergamon Press.

Husen, T. and Tuijman, A. (1991). The contribution of formal schooling to the increase in intellectual capital, Education Researcher, 20(7), 17-25.

Lipman, M.(1985). Philosophy Goes to School. Philadelphia: Temple University Press

Maslow, M. (1998). Toward a Psychology of Being ( $3^{\text {rd }}$ $E d)$. New York: Van Nostrand.

Department of Education (2002). Curriculum Stocktake Report to the Minister of Education. Wellington: Department of Education.

Piaget, J. (1953). The Origin of Intelligence in Children London: Routledge.

Stephenson, J. and Scobie, G. (2002). The Economics of Population Ageing. New Zealand Treasury Working Papers, 02/05. Wellington: The Treausry.

Van der Veer R. and Valsiner, J. (1994). The Vygotski Reader. Oxford: Blackwells.

Vygodskaya, G.L. and Lifanova, T.M. (1999). Lev Semenovitch Vygotski, Journal of Russian and Eastern European Psychology, 37(4), 3-99
Wasmer, E. (1998). Labour Supply Dynamics, Unemployment and Human Capital Investments. Seminar Paper No. 651 Institute of Economic Studies. Stockholm: Stockholm University.

Welch, D.E. and Worm, V. (2006). International business travellers: A challenge for IHRM, In Stahl, G.K. and Bjorkman, I. Handbook of Research in International Human Resource Management, Cheltenham: Edward Elgar.

\section{Authors}

Mark J. Williams

Director

Williams Construction

229 Portage Road

Papatoetoe

Auckland

m.jwilliams@xtra.co.nz

Alan Williams

Director

Williams and Partners Ltd

94 Slacks Road

Riverdale

Palmerston North

A.Williams@massey.ac.nz 